DOI 10.37882/2223-2974.2021.01.13

\title{
ОСОБЕННОСТИ РАЗВИТИЯ И РОЛЬ ТУРИЗМА В ЭКОНОМИКЕ ОТДЕЛЬНЫХ СТРАН
}

\section{FEATURES OF DEVELOPMENT AND ROLE OF TOURISM IN THE ECONOMY INDIVIDUAL COUNTRIES}

\section{E. Kutyashova}

Summary: The article examines certain aspects of the development of the tourism sector of countries, in the gross domestic product of which it occupies more than $25 \%$. An analysis of the arrivals of foreign tourists and their expenses has been carried out. The factors that determine the development of tourism are highlighted. The indicators of the development and competitiveness of tourism in Iceland, Georgia, Cambodia, Albania and Croatia are considered. Conclusions are made about the role of tourism in the economic development of countries with a high share of tourism in GDP.

Keywords: tourism, economic development, gross domestic product, tourism share in GDP, foreign tourist arrivals, international tourist spending, competitiveness.
Кутяшова Елена Васильевна

К.э.н., дочент, ФГБОУВО «Удмуртский государственный университет» 9128504681@mail.ru

Аннотация: В статье рассмотрены отдельные аспекты развития сферы туризма стран, в валовом внутреннем продукте которых он занимает долю более $25 \%$. Проведен анализ прибытий иностранных туристов и их расходов. Выделены факторы, определяющие развитие туризма. Рассмотрены показатели развития и конкурентоспособности туризма в Исландии, Грузии, Камбоджи, Албании и Хорватии. Сделаны выводы о роли туризма в экономическом развитии стран с высокой долей туризма в ВВП.

Ключевые слова: туризм, экономическое развитие, валовой внутренний продукт, доля туризма в ВВП, прибытия иностранных туристов, расходы международных туристов, конкурентоспособность.
$\mathrm{T}$ уризм в современных условиях является одним из двигателей мирового экономического развития. Туризм относится к быстрорастущим секторам мировой экономики и по своему вкладу в валовой внутренний продукт (ВВП) опережает производство автомобилей, химикатов, добычу полезных ископаемых, сельское хозяйство и банковскую деятельность. Развитие туризма оказывает значимое положительное влияние на рост экономики и может являться его источником [1]. Туризму отводится важная роль в обеспечении устойчивого социально-экономического развития страны [2].

Особенностью туризма является возможность оказывать влияние на развитие смежных отраслей. Так, туризм влияет на развитие производства потребительских товаров, транспорта и связи, сельского хозяйства и строительства. Туризм играет важную роль в занятости населения различных секторов экономики, является источником валютных поступлений. Большая часть туристских услуг производится с минимальными затратами, при этом туризм стимулирует приток инвестиций в инфраструктуру.

Особое значение туризм приобретает в странах, для которых он является основным источником доходов населения и важной статьей формирования ВВП. В связи с этим, представляется актуальным рассмотрение особенностей развития сферы туризма в странах с высокой до- лей данного сектора в ВВП, а также соотношение темпов роста вклада туризма и темпов роста ВВП. Для анализа выделена группа стран с долей туризма в ВВП более $25 \%$, в соответствии с трехступенчатой шкалой, разработанной Всемирной туристической организации (ВТО) [3]. Были рассчитаны средние темпы роста за 2010-2019 гг. общего вклада туризма в ВВП, прибытий и расходов иностранных туристов, а также ВВП. Для расчета среднего коэффициента роста использована средняя геометрическая.

Рассмотрим страны с высокой долей туризма в ВВП (табл.1) [4]. Большая часть стран с долей туризма в ВВП более 25 \% относится к малым островным государствам. В основном, это островные страны Америки - Антигуа и Барбуда, Багамы, Барбадос, Гренада, Доминика, СентКитс и Невис, Сент-Винсент и Гренадины, Ямайка; островные страны Африки - Кабо Верде, Сейшельские острова; островные страны Океании - Вануату, Фиджи. Для большинства туризм давно является основной статьей в формировании ВВП, что подтверждается данными за 2000, 2010 и 2019 годы. По уровню экономического развития в основном - это экономически среднеразвитые страны Кабо Верде, Белиз, Мальдивы, Фиджи, Доминика, Ямайка [5]. Среди стран сравнительно недавно преодолевших барьер по доле туризма в ВВП 25 \% - Исландия, Грузия, Камбоджа, Албания, Хорватия, Сан Томе и Принсипи, при этом островными государствами являются только 
Исландия и Сан Томе и Принсипи. Далее страны традиционно имеющие высокую долю вклада туризма в ВВП и страны недавно вошедшую в эту группу будут рассмотрены отдельно.

Таблица 1

Страны с долей туризма в ВВП более 25\%.

\begin{tabular}{|l|c|c|c|}
\multirow{2}{*}{ Страны } & \multicolumn{3}{|c|}{ Доля туризма в ВВП, \% } \\
\cline { 2 - 4 } & 2019 г. & 2010 г. & 2000 г. \\
\hline Макао & 72,0 & 76,9 & 47,3 \\
\hline Сальдивы & 66,1 & 69,8 & 44,8 \\
\hline Сент-Китс и Невис & 65,8 & 64,0 & 54,6 \\
\hline Гренада & 62,6 & 48,0 & 44,1 \\
\hline Вануату & 55,8 & 41,1 & 46,5 \\
\hline Кабо Верде & 48,2 & 51,1 & 59,3 \\
\hline Сент-Винсент и Гренадины & 46,2 & 41,9 & 17,3 \\
\hline Антигуа и Барбуда & 46,2 & 37,3 & 52,7 \\
\hline Белиз & 44,7 & 52,3 & 52,7 \\
\hline Сент-Люсия & 44,7 & 33,9 & 22,5 \\
\hline Багамы & 43,0 & 35,7 & 42,7 \\
\hline Фиджи & 40,3 & 39,1 & 34,6 \\
\hline Доминика & 40,0 & 40,0 & 28,2 \\
\hline Барбадос & 38,0 & 38,9 & 35,4 \\
\hline Ямайка & 36,2 & 37,9 & 34,4 \\
\hline Исландия & 34,7 & 27,5 & 26,0 \\
\hline Грузия & 33,8 & 19,4 & 18,3 \\
\hline Камбоджа & 33,5 & 14,2 & 15,0 \\
\hline Сан Томе и Принсипи & 32,7 & 26,9 & 14,9 \\
\hline Албания & 27,4 & 13,5 & 18,5 \\
\hline Хорватия & 27,0 & 23,8 & 17,3 \\
\hline
\end{tabular}

Составлено автором на основании мирового атласа данных [4]

Рассмотрим прибытия иностранных туристов и расходы международных туристов внутри страны в постоянных ценах 2011 года за период с 2010 по 2019 год [6,7]. Для анализа рассчитаем средние темпы роста этих показателей с использованием средней геометрической (рисунок 1).

Практически все страны демонстрируют положительную динамику, при этом средний коэффициент роста прибытий опережает средний коэффициент роста расходов иностранных туристов. Доля расходов международных туристов в общем туристском потреблении в этих странах составляет 70-100 \% [7]. Самые высокие средние темпы прироста по прибытию иностранных ту- ристов показали: Кабо Верде - 9,8\%, Сейшельские острова - 9,5\%, Белиз - 9,2\%. Высокие средние темпы прироста расходов иностранных туристов демонстрируют Мальдивы - 6\%, Гренада, Белиз -5,8\%. Число туристов и туристских расходов в Доминике имеют общую тенденцию к снижению, что связано с природными катастрофами 2015 г. (тропический шторм Эрика) и 2018 г. (ураган Мария). Обе катастрофы практически парализовали индустрию туризма. Министерство туризма Доминики реализует ряд инициатив, рассчитывая в перспективе на восстановление туристских потоков.

Туристский потенциал островных государств предопределяется такими факторами, как: богатый природно-рекреационный потенциал; развитие как основных видов туризма (пляжный, экскурсионный, этнографический), так и экзотических (событийный); благоприятная экологическая обстановка [8].

Среди основных проблем развития островных государств традиционно выделяют структурную слабость экономики и объективное ограничение возможностей роста, высокую восприимчивость к внешним экономическим потрясениям, катастрофам природного и антропогенного характера, как следствие уязвимость к последствиям снижения туристских потоков [9].

Рассмотрим темпы роста ВВП и темпы роста вклада туризма в ВВП островных государств в постоянных ценах за период с 2010 по 2019 год [10,11]. Для анализа рассчитаем средние коэффициенты роста этих показателей с использованием средней геометрической (рисунок 2).

Все страны демонстрируют положительную динамику как по вкладу туризма в ВВП, так и по ВВП в целом, у большинства средние темпы роста вклада туризма в ВВП опережают средние темпы роста ВВП. Таким образом, можно сделать вывод о положительном в целом влиянии индустрии туризма на социально-экономическое развитие этих стран.

Рассмотрим развитие туризма в Исландии, Грузии, Камбодже, Албании и Хорватии (табл. 2). Одной из стран, демонстрирующей высокие средние темпы прироста вклада туризма в ВВП, является Грузия. В 2015 году Правительством Грузии принята «Стратегия развития туризма в Грузии - 2025», в соответствии с которой туризм является основой устойчивого развития страны. Современная стратегия развития туризма в Грузии нацелена на увеличение продолжительности пребывания иностранных туристов в стране, основной упор по продвижению грузинского турпродукта делается на экономически развитые страны и на Россию. Одним из важнейших факторов, влияющих на привлечение туристов, является наличие быстрого, комфортабельного, сравнительно недорогого транспортного сообщения [12]. 


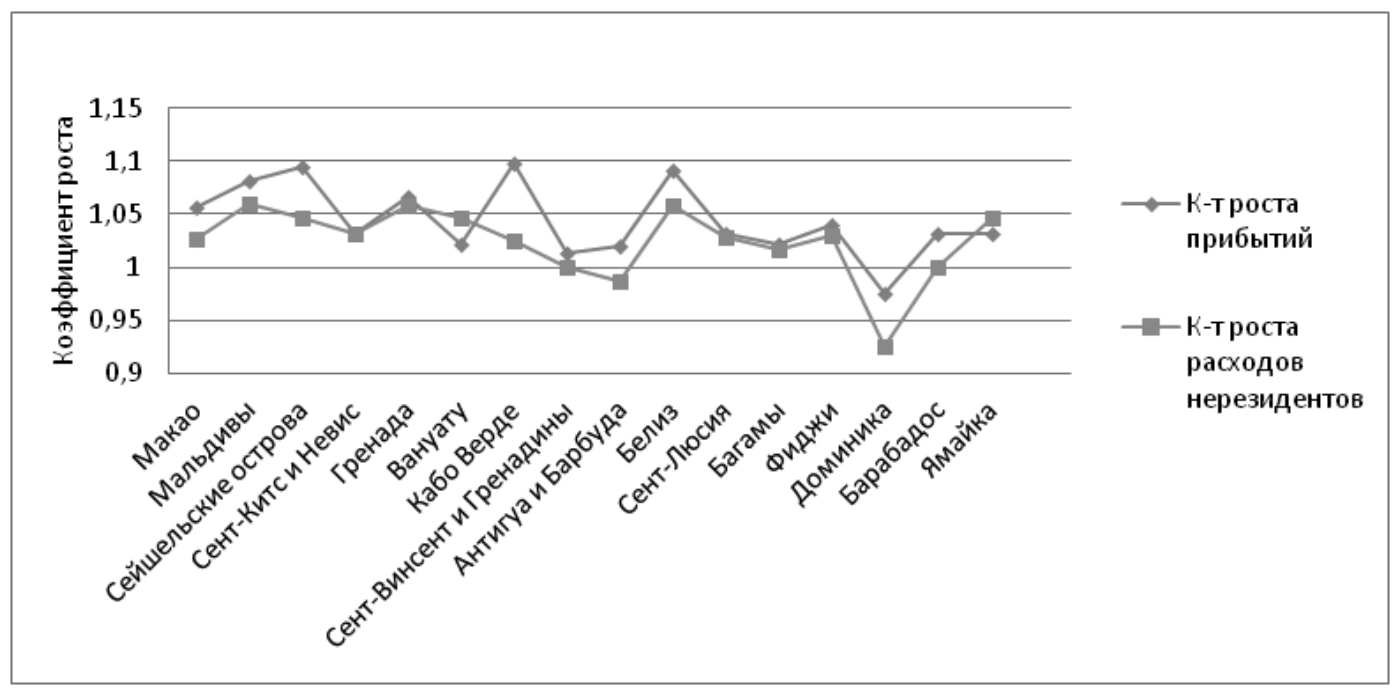

Рис. 1. Средние коэффициенты роста прибытий и расходов иностранных туристов за период 2010-2019 гг. стран с долей туризма в ВВП более 25 \%

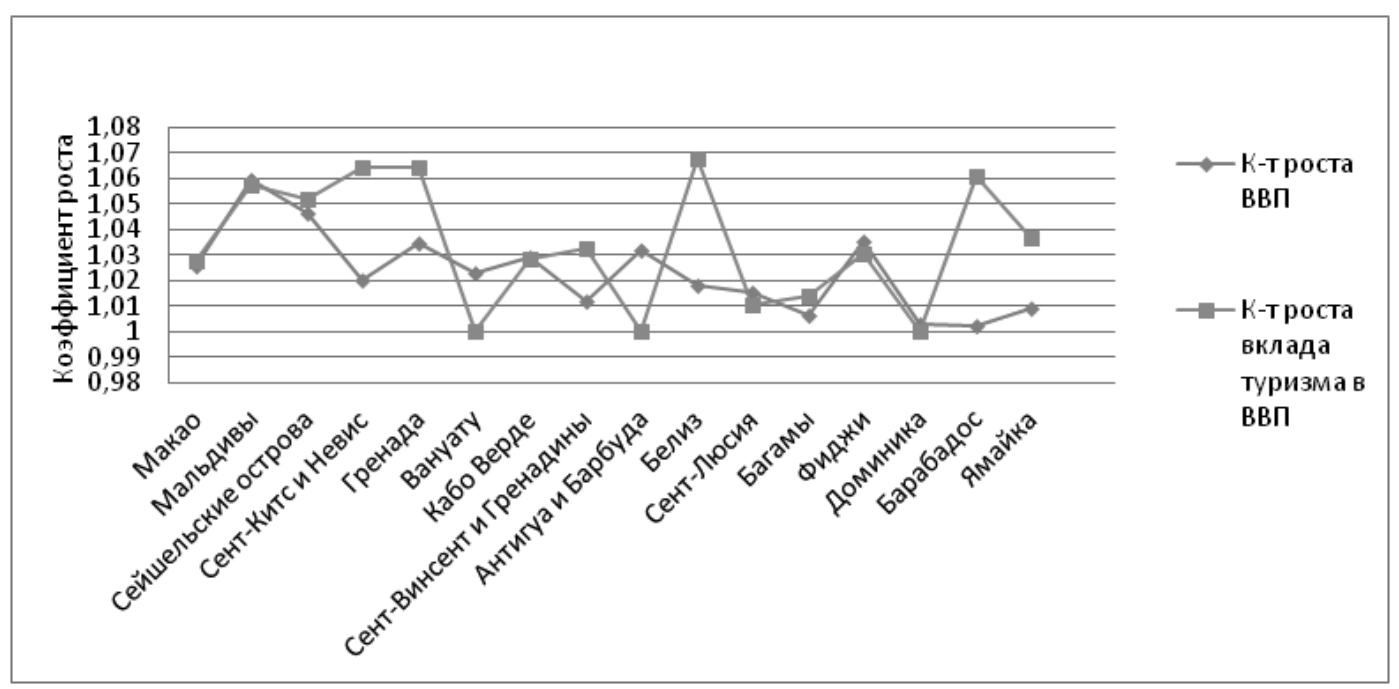

Рис. 2. Средние коэффициенты роста ВВП и вклада туризма в ВВП за период 2010-2019 гг.

Таблица 2

Развитие туризма в странах с долей туризма в ВВП более $25 \%$

\begin{tabular}{|l|c|c|c|c|}
\hline Страны & $\begin{array}{c}\text { Средний темп прироста } \\
\text { вклада туризма в ВВП за } \\
2010-2019 \text { гг., \% }\end{array}$ & $\begin{array}{c}\text { Средний темп прироста } \\
\text { туристских прибытий 3а } \\
2010-2018 \text { гг., \% }\end{array}$ & $\begin{array}{c}\text { Средний темп прироста } \\
\text { расходов международных } \\
\text { туристов за 2010-2019 гг., \% }\end{array}$ & $\begin{array}{c}\text { 0бщий вклад туризма в } \\
\text { занятость 2019 г., \% }\end{array}$ \\
\hline Исландия & 10,2 & 21,6 & 15,5 & 35,1 \\
\hline Грузия & 15,6 & 20,5 & 20,0 & 29,4 \\
\hline Камбоджа & 9,4 & 12,0 & 9,9 & 32,5 \\
\hline Албания & 4,4 & 11,8 & 3,6 & 25,0 \\
\hline Хорватия & 3,7 & 7,8 & 5,9 & 23,3 \\
\hline
\end{tabular}

Рассчитано автором на основании мирового атласа данных $[4,6,7]$

Бум въездного туризма в Исландии наблюдается с 2000-х годов, главной достопримечательностью которой является ее уникальная природа, что предопределило основное направление туризма - экологическое [13].
Туризм для Камбоджи является второй по значимости после производства и экспорта одежды статьей доходов бюджета страны. Камбоджа привлекает туристов экзотической природой и рекреационными ресурсами. 
Наиболее востребованными направлениями туризма являются культурное, экологическое и гастрономичеCKoe [14].

Рассмотрим средние темпы прироста туристских расходов международных туристов и резидентов внутри страны (рисунок 3). На основании расчетов, мы видим, что средние темпы роста расходов нерезидентов превышают средние темпы роста расходов резидентов, за исключением Албании, в которой в качестве цели посещения иностранные туристы на втором месте указывают транзит. Туризм в Албании занимает третье по значимости место в развитии экономики после сельского хозяйства и промышленности. Основными видами туризма, развиваемыми в Албании, являются познавательный, пляжный, экологический и спортивный туризм.

Одним из важнейших факторов, влияющих на развитие сферы туризма, является наличие современной туристской инфраструктуры. Развитие туристской инфраструктуры требует значительных капиталовложений. Соотношение темпов экономического роста с объемом инвестиций позволяет судить об эффективности проводимой инвестиционной стратегии [15]. Рассмотрим соотношение средних темпов роста общего вклада туризма в ВВП и капиталовложений в сферу туризма Исландии, Грузии, Камбоджи, Албании и Хорватии (рисунок 4).

Мы видим, что средние темпы роста вклада туризма в ВВП превышают средние темпы роста капиталовложе- ний в туристскую отрасль (за исключением Камбоджи), что свидетельствует об эффективности инвестиционной политики, проводимой в сфере туризма. Опережающие темпы роста капиталовложений в туриндустрию Камбоджи объясняются проводимой политикой усиления частного и государственного инвестирования туристской инфраструктуры. Примером может служить строительный бум в провинции Сиануквиль.

Рассмотрим слабые и сильные стороны Исландии, Грузии, Камбоджи, Албании и Хорватии на мировом рынке туристских услуг (табл. 3). Для этого воспользуемся данными рейтинга стран по индексу конкурентоспособности путешествий и туризма в 2019 году [16].

Высокое положение в рейтинге Исландия обеспечила за счет высокого уровня безопасности туристского отдыха, медицинского обеспечения и информационнокоммуникационных технологий - компонентов субиндекса конкурентоспособности A «Благоприятная среда», а также высокого уровня развития инфраструктуры туристских услуг - компонента субиндекса С «Инфраструктура». Хорватия заняла 27 место в рейтинге конкурентоспособности сферы туризма и путешествий за счет низких цен на туристские услуги - компонента субиндекса В «Политика и создание благоприятных условий в индустрии туризма и путешествий», а также высокого уровня развития туристской инфраструктуры и привлекательности природы. Грузия, занимает 68 место в рейтинге за счет создания благоприятной среды в турист-

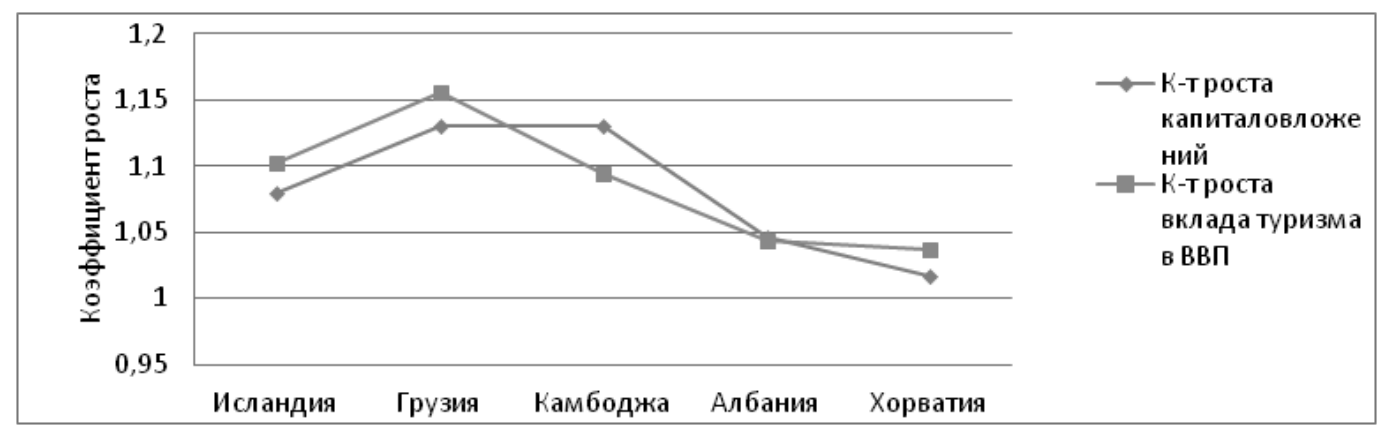

Рис. 4. Средние коэффициенты роста вклада туризма в ВВП и капиталовложений за период 2010-2019 гг.

Таблица 3

Рейтинг стран с долей туризма в ВВП более 25 \% по индексу конкурентоспособности в сфере туризма за 2019 г.

\begin{tabular}{|l|c|c|c|c|c|}
\hline \multirow{2}{*}{\multicolumn{1}{r|}{ Страны }} & Место в рейтинге & \multicolumn{4}{|c|}{ в том числе по субиндексу: } \\
\cline { 3 - 6 } & & A & B & C & D \\
\hline Исландия & 30 & 4 & 33 & 19 & 71 \\
\hline Грузия & 68 & 40 & 40 & 66 & 106 \\
\hline Камбоджа & 98 & 106 & 78 & 101 & 72 \\
\hline Албания & 86 & 64 & 95 & 88 & 94 \\
\hline Хорватия & 27 & 62 & 22 & 31 & 23 \\
\hline
\end{tabular}

Составлено автором на основании Доклада о глобальном индексе конкурентоспособности в сфере туризма [14] 


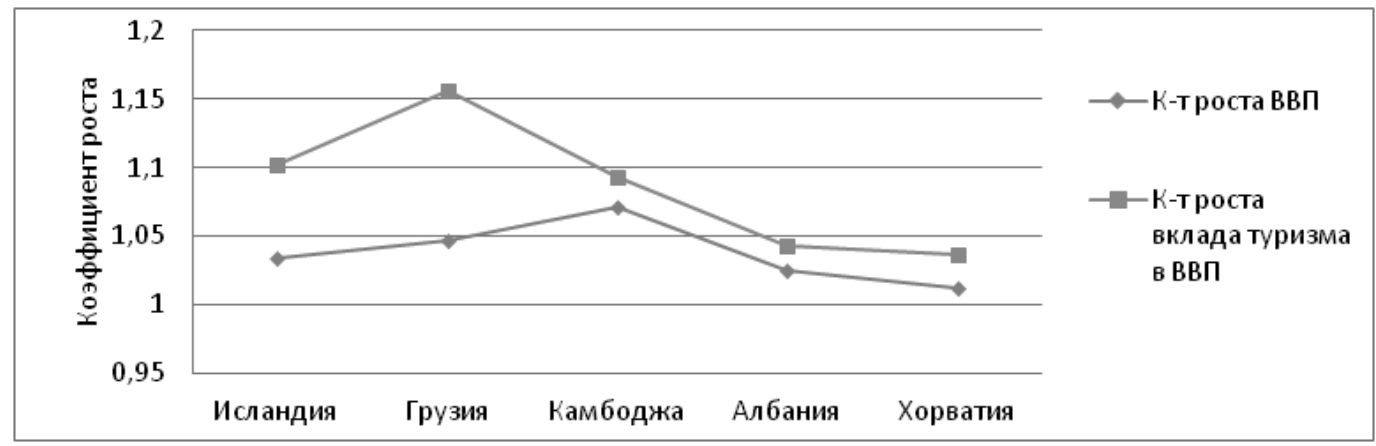

Рис. 5. Средние коэффициенты роста ВВП и вклада туризма в ВВП за период 2010-2019 гг.

ской сфере - быстроты и низкой стоимости открытия бизнеса, наличие эффективной законодательной базы и налоговых стимулов, высокая степень безопасности, а также активной политике по продвижению Грузии на мировом туристском рынке.

Для оценки роли туризма в устойчивом развитии экономики рассмотрим соотношение темпов роста ВВП и темпов роста вклада туризма в ВВП (рисунок 5).

Все пять стран демонстрируют опережающие темпы роста вклада туризма в ВВП по отношению темпу роста ВВП страны. Средний темп прироста ВВП за 2010-2019 гг. колеблется от 1,3 \% в Хорватии до 7,2 \% в Камбодже.

Подводя итоги, можно сделать следующие выводы:

- среди стран с долей туризма в ВВП более 25 \% преобладают малые островные государства, для которых сфера туризма является основным возможным источником экономического роста и развития;

- большинство стран данной группы демонстрируют положительную динамику по прибытиям и расходам иностранных туристов, по вкладу туризма в ВВП и ВВП в целом;

- развитие туризма в этой группе стран предопределяется богатым природно-рекреационным потенциалом, благоприятной экологической об- становкой; основными видами туризма являются экологический, пляжный, экскурсионный, этнографический, экзотический;

- к основным рискам развития туризма следует отнести снижение туристских потоков вследствие природных катастроф и эпидемий (например, COVID-2019);

- странами, недавно преодолевшими барьер по доле туризма в ВВП 25\%, являются Грузия, Камбоджа, Албания, Хорватия, Исландия, Сан Томе и Принсипи, при этом островными являются только последние две;

- Грузия, Камбоджа, Албания, Хорватия и Исландия демонстрируют высокие средние темпы роста вклада туризма в ВВП, прибытий и расходов международных туристов, при этом туризм не является основной статьей доходов; средние темпы роста вклада туризма в ВВП опережают средние темпы роста ВВП.

Таким образом, туризм может рассматриваться в качестве катализатора социально-экономического развития стран. Несмотря на кризисные явления в туризме, вызванные пандемией COVID-2019, данный сектор экономики способен на быстрое восстановление и возобновление роста, в том числе за счет отложенного спроса и предпринимаемых мер государственной поддержки развития туризма.

\section{ЛИТЕРАТУРА}

1. Аистов А.В., Николаева Т.П. Гипотеза о стимулирующем воздействии туризма на ВВП // Прикладная эконометрика. 2019. Т.56. С. 5-24

2. Болдырева С.Б. Влияние туризма на социально-экономическое развитие региона: обобщение российского и зарубежного опыта // Региональная экономика: теория и практика. 2018. Т.16. Вып. 5. С. 972-988

3. Международные рекомендации по статистике туризма. Официальный сайт Всемирного совета по путешествиям и туризму BT0 http://wttc.org/

4. Туризм, общий вклад в ВВП (доля, \%), мировой атлас данных // http://knoema.ru/atlas/topics/Тyризм/0бщий-вклад-туризма-в-ВВП/0бщий-вклад-вВВП-доля-реrcent

5. Рейтинг стран мира по уровню валового национального дохода на душу населения // http://gtmarket.ru/ratings/gross-national-income-ranking

6. Прибытия иностранных туристов. Мировой атлас данных // https://knoema.ru/atlas/topics/Туризм/Показатели-въездного-туризма/Прибытия

7. Расходы международных туристов внутри страны, в постоянных ценах 2011 г. Мировой атлас данных // http://knoema.ru/atlas/topics/Typизм/ Рacходымеждународных-туристов-внутри-страны-в-постоянных-ценах-2011-г-млрд-долл-США

8. Гуров С.А., Молчанова Е.А. Географические тенденции развития туризма в экзотических островных дестинациях // Геополитика и экогеодинамика 
регионов. 2018. Т. 4 (14). Вып.4. С. 159-166

9. Пырцов Н.И. Проблемы развития туризма в развивающихся островных государствах и территориях // Вестник Санкт-Петербургского университета. Сер.7. 2012. Вып.1. С. 99-106

10. ВВП в постоянных ценах 2010 г. (долл. (ША), мировой атлас данных // http://knoema.ru/atlas/Becь-мир/topics/Экономика/Национальные-счета-Валовой-внутренний-продукт/ВВП-в-постоянных-ценах-2010-г-долл-США

11. Общий вклад туризма в ВВП, в постоянных ценах 2011 г. (млрд. долл. (ША), мировой атлас данных // https://knoema.ru/atlas/Becb-мир/topics/Typизм/ 0бщий-вклад-туризма-в-ВВП/0бщий-вклад-в-ВВП-в-постоянных-ценах-2011-г-млрд-долл-США

12. Деточенко Л.В. Особенности развития туризма в Грузии как отрасли, способствующей экономическому росту страны // Вестник Удмуртского университета. 2019. Т.29. Вып.2. С. 279-289

13. Сафина С.С., Амосова Г.М. Современные особенности развития международного туризма в странах Северной Европы // Известия СПбГэУ. 2018. № 4 (112) C. 38-43

14. Бурова Е.С. Тенденции развития туристической отрасли Камбоджи. // Восточная Азия: факты и аналитика. 2019. № 1. С. 15-23

15. Кутяшова Е.В., Скобелева 0.А. Влияние капиталовложений на развитие туризма в экономически среднеразвитых странах // Современная наука: актуальные проблемы теории и практики. 2020. №11-2. С. 26-31

16. Доклад о глобальном индексе конкурентоспособности в сфере туризма и путешествий 2019// http://www3.weforum.org/docs/WEF_TTCR_2019.pdf

() Кутяшова Елена Васильевна (9128504681@mail.ru).

Журнал «Современная наука: актуальные проблемы теории и практики»

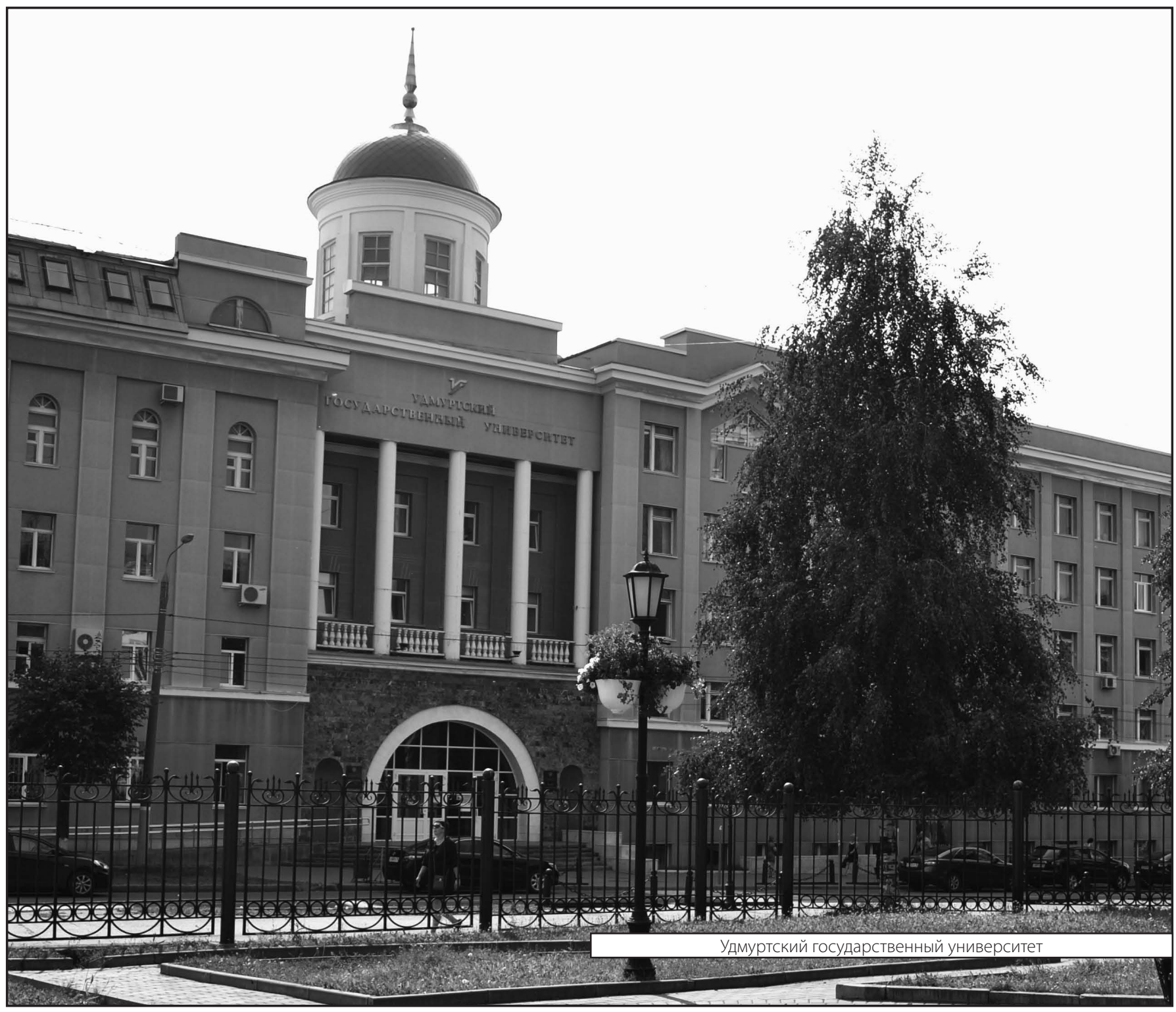

